\title{
A SP survey-based method for evaluating environmental performance of urban commercial districts: A case study in Beijing
}

\author{
Fang Wang ${ }^{a}$, Yan $\mathrm{Li}^{\text {b, }}{ }^{*}$, Xiaolu Gao ${ }^{\mathrm{c}}$ \\ a School of Public Management of Inner Mongolia University, China \\ ${ }^{\mathrm{b}}$ College of Asia Pacific Studies, Ritsumeikan Asia Pacific University, Japan \\ ${ }^{\mathrm{c}}$ Institute of Geographic Sciences and Natural Resources Research, Chinese Academy of Sciences, China
}

\section{A R T I C L E I N F O}

\section{Article history:}

Received 18 August 2015

Received in revised form

25 November 2015

Accepted 26 November 2015

Available online 14 December 2015

\section{Keywords:}

Urban commercial district

Environmental performance

SP survey

\begin{abstract}
A B S T R A C T
Environmental assessment plays an important role in directing urban development towards a sustainable way. Unfortunately the majority of currently available environmental assessment tools emphasize either the regional scale or single-building scale, while giving less attention to the meso-scale. This paper presents a methodology of meso-scale environmental performance assessment for urban commercial districts. It extends both the environmental performance assessment and the environmental efficiency assessment by integrating the indicators from three aspects, i.e. the environmental quality, the social and economic value, and the environmental load. Consumer satisfaction is also incorporated. The Stated Preference survey (SP survey) was introduced for the evaluation to get the preference of the consumers, and weights of the indicators were decided via discrete choice model fitting. Six typical commercial districts of Beijing were sampled to test the viability. The results of our research are proved helpful for understanding the environmental situation of urban commercial districts therefore instructive for city planning and management. The proposed method can also be applied to other meso-scale districts such as industrial districts and residential districts in city.
\end{abstract}

(๑) 2015 Elsevier Ltd. All rights reserved.

\section{Introduction}

Urban commercial districts are key functional areas in cities where businesses are concentrated and numerous transactions take place. They offer congenial space for shopping, entertainment and leisure activities, and are therefore instrumental in generating great profits for the economy. However, urban commercial districts face many environmental challenges such as noise, light, and air pollution. Significant amounts of carbon emissions are generated by the large volumes of traffic and services found within urban commercial districts (ICF International, 2007). A key issue is how to guide urban commercial districts towards ecological civilization, thereby reconciling the contradictions between economic development and the environment. In this context, environmental assessment is increasingly being viewed as an important tool to aid in the shift towards urban sustainable development (Wu and Wu, 2012).

\footnotetext{
* Corresponding author. College of Asia Pacific Studies, Ritsumeikan Asia Pacific University, 1-1 Jyumonji-baru, Beppu, Oita, 874-8577, Japan.

E-mail address: yanli@apu.ac.jp (Y. Li).
}

Environmental assessment of urban areas is conducted over a wide range of spatial scales, which can be classified as macro, meso, and micro. Macro or national/regional scale environmental assessments have been applied widely (Haapio, 2008, 2012; Xu, 2006). Examples of empirical studies taking the macro-scale approach include; environmental impact assessment (George and Kirkpatrick, 2007; Lee, 2007), strategic environmental assessment (Marull et al., 2007; Putzhuber and Hasenauer, 2010), environmental quality assessment (Esty et al., 2008; Mori and Christodoulou, 2012), objectives-led SEA, environmental efficiency assessment (Charmondusit and Keartpakpraek, 2011; Zaim, 2004), and the environmental performance assessment (Esty et al., 2008; Mori and Christodoulou, 2012; Lu and Cao, 2011). All these studies propose objective indicators and methods to address well defined problems. Therefore furnished with a macro or large scale overview of integrated nature-society systems and objective decision making criteria, policy makers can make informed decisions for guiding urban areas towards sustainable development (Huang \& Chen, 1999).

There are also many available environmental performance assessment tools that have been created specifically for micro or 
single-building level assessments. Examples of such tools include; BREEAM (Building Research Establishment Environmental Assessment Methodology), NABERS (National Australian Building Environmental Rating System), GBC (Green Building Challenge), CASBEE (Comprehensive assessment system for building environmental efficiency).

Unfortunately most of the available environmental assessment tools focus on either the macro or single-building scales (Scipioni et al., 2009; Seppalaa et al., 2005), while giving less attention to the meso-scale. The meso-scale, covers commercial districts, residential districts, industrial district, etc., and it can offer valuable guidance on planning and managing cities. Comparisons of environmental assessment results of several meso-scale districts within a single city can give useful reference information for planning the configuration of urban facilities and for spatial optimization. In recent years, a few studies have demonstrated environmental performance assessments of residential districts (Sharifi and Murayama, 2013; Dizdaroglu, 2015). For instance, Ji and Gao (2011) constructed a performance evaluation system of the urban residential areas using the ratio of environmental quality and environmental impact. Additionally LEED for Neighborhood Development and BREEAM Communities were published recently, as expansions of the single building assessment. However we lack demonstrations or case studies of environmental performance assessments of commercial districts.

This paper draws knowledge from environmental performance assessment of buildings and residential districts, and proposes a methodology for assessing environmental performance of urban commercial district. The weights of indicators were computed via the Stated Preference (SP) method. Case studies on commercial districts in Beijing were carried out to test its viability.

\section{Environmental performance assessment system for commercial districts}

The commercial district environment is a complex concept; and it can be defined in various ways depending on field of study i.e. economics, architecture, and environmental studies (Dhakal, 2003). This arises from the fact that commercial districts have many functions for a city, including economic, social and environmental functions. It is therefore important to consider all these aspects in the assessment of commercial districts.

Since commercial districts are urban key functional areas like the residential district, we should also draw knowledge from the environmental assessment of the residential districts. There are a variety of methodologies or tools designed for environmental evaluation of residential districts. Some of them assess the impacts of the residential districts to the climate, resources and ecology and they belong to environmental impact assessment. For instance, BREEAM focuses on mitigating the overall environmental impacts of the studied area especially on the climate and energy; its indicators emphasize on reducing $\mathrm{CO}_{2}$ as well as sustainable and efficient use of resources (Sev, 2011). Another group of assessment is concerned with the environmental quality of buildings; so they are a part of the environmental quality evaluation. For example, Dizdaroglu (2015) proposed a set of key micro-level urban ecosystem indicators for monitoring the sustainability of residential developments. The indicator framework measures the sustainability performance in 3 main categories including: natural environment, built environment, and socio-economic environment. The LEED also pays attention to the environmental quality of buildings. However the CASBEE is very special; it encompasses environmental quality and environmental impact evaluation by computing the ratio of environmental quality to environmental load. It not only applies the concept of environmental efficiency (Seppalaa et al., 2005; Xu et al.,
2010), but also integrates the indicators into one or several indices which can lead to a better understanding and a convenient comparison of the overall situation. Therefore, the idea of CASBEEbased environmental assessment was adopted in this paper for urban commercial districts. We refined the indicators to meet our purpose and the situation of China. Furthermore, in order to take into account the characteristics of commercial districts and the satisfaction of the customers with the environment, we added some other indicators (e.g. management and level of satisfaction), thereby paying more attention to people's satisfaction, rather than using objective indicators only.

\subsection{Assessment system}

Inspired by the composition of the Japanese CASBEE and the idea of environmental efficiency, and considering the multifunctional nature of the commercial districts for a city, we extend the assessment from environmental quality only to a comprehensive assessment from economy, society and environment quality. More specifically, environmental performance in this paper refers to the environmental, economic and social values associated with the environmental loads (pressures) that have been generated in the area. We assess the environment of a commercial district on three aspects: environmental quality $(\mathrm{Q})$, social \& economic value $(S)$ and environmental load (L) using the following equation:

$\mathrm{CEE}=\frac{\mathrm{Q}+\mathrm{S}}{\mathrm{L}}=\frac{\sum_{\mathrm{i}=1}^{\mathrm{n}}\left(\mathrm{w}_{\mathrm{qi}} * \mathrm{D}_{\mathrm{qi}}\right)+\sum_{\mathrm{j}=1}^{\mathrm{m}}\left(\mathrm{w}_{\mathrm{sj}} * \mathrm{D}_{\mathrm{sj}}\right)}{\sum_{\mathrm{k}=1}^{\mathrm{C}}\left(\mathrm{w}_{\mathrm{lk}} * \mathrm{D}_{\mathrm{lk}}\right)}$

where CEE denotes the score of Commercial district Environmental Efficiency, Q denotes the score of environmental quality, $\mathrm{S}$ that of the social and economic value, and $L$ that of the environmental load. $D_{q}, D_{s}$ and $D_{1}$ denotes the specific score of non-dimensional indicators for environmental quality, social \& economic value and environmental load, respectively; $\mathrm{w}_{\mathrm{q}}, \mathrm{w}_{\mathrm{s}}$ and $\mathrm{w}_{\mathrm{l}}$ their weights; $\mathrm{i}, \mathrm{j}$, and $\mathrm{k}$ refer to the individual indicators and $\mathrm{n}, \mathrm{m}$, and $\mathrm{c}$ their total numbers. We assume that environmental quality, social \& economic value and environmental load have equal importance and define $\sum_{\mathrm{i}=1}^{\mathrm{n}} \mathrm{w}_{\mathrm{q}}=1.0, \sum_{\mathrm{i}=1}^{\mathrm{n}} \mathrm{w}_{\mathrm{s}}=1.0, \sum_{\mathrm{i}=1}^{\mathrm{n}} \mathrm{w}_{\mathrm{l}}=1.0$. Hence CEE can be close to 0.0 when $Q+S$ is very small. Conversely, if $L$ is very small, i.e. the environmental load is low enough, the CEE can be very high.

\subsection{Indicators}

The indicators we adopted for the assessment are given in Table 1, consisting of eighteen factors for environmental quality (Q), four factors for social \& economic value (S) and eight factors for environmental load (L).

\subsection{SP-based weight model}

The common methods for allocating weights to indicators are classified into two main categories: subjective methods e.g. AHP, principal component analysis (Du, Meng, \& Ma, 2012) and objective method e.g. entropy method and gray relational analysis (Zhang et al., 2013). The subjective method represents experience and knowledge of decision-makers, because weight allocation is based on subjective judgment of experts. However, this method is highly arbitrary. The objective method computes statistical weights using internal properties of indicators of evaluated objects and interrelations between them. But it lacks a priori knowledge from experts and its accuracy is heavily dependent on data quality. In recent years, the Stated Preference (SP) method has been proposed 
Table 1

Indicator system for assessing urban commercial district environment.

\begin{tabular}{|c|c|c|c|}
\hline Level-1 indicator & Level-2 indicator & Level-3 indicator & Rating factors \\
\hline \multirow{9}{*}{$\begin{array}{l}\text { Environmental Quality } \\
\text { (Q) }\end{array}$} & \multirow{3}{*}{$\begin{array}{l}\text { Q1 natural } \\
\text { environment }\end{array}$} & Green space quality & Green rate, green landscape quality \\
\hline & & Water body quality & Water body area ratio, water landscape quality \\
\hline & & Microclimate & Human comfort \\
\hline & \multirow{6}{*}{$\begin{array}{l}\text { Q2 human } \\
\text { environment }\end{array}$} & Traffic conditions & Bus and metro accessibility, traffic control, number of berths in parking lot, road area ratio \\
\hline & & $\begin{array}{l}\text { Safety and disaster } \\
\text { prevention }\end{array}$ & Open space quality, public security, security facilities \\
\hline & & Surrounding facilities & Applicability of convenience facilities and accessibility facilities \\
\hline & & Service management & $\begin{array}{l}\text { Ability to solve problems of businesses and customers, ability to solve and process } \\
\text { administrative affairs }\end{array}$ \\
\hline & & Hygiene & Clean and maintain the streets \\
\hline & & Mental and aesthetic needs & Aesthetics of landscapes consisting of buildings, water bodies and greeneries \\
\hline \multirow{4}{*}{$\begin{array}{l}\text { Social\&Economic value } \\
\text { (S) }\end{array}$} & \multirow{2}{*}{ S1 social values } & Protection of special scenes & Protection of existing historical buildings and relics \\
\hline & & Fame of the city & Ability to represent the image of the entire area \\
\hline & \multirow[t]{2}{*}{ S2 economic values } & Size and number of shops & Size and number of shops \\
\hline & & $\begin{array}{l}\text { Type and grade of } \\
\text { businesses }\end{array}$ & Types, numbers and grades of businesses \\
\hline \multirow[t]{8}{*}{ Environment Load (L) } & \multirow{3}{*}{ L2 traffic load } & Building density & Building coverage \\
\hline & & Vehicular traffic & Traffic \\
\hline & & Human traffic & Traffic of local people and non-local people \\
\hline & \multirow[t]{5}{*}{ L3 pollution load } & Noise pollution & Noise pollution \\
\hline & & Light pollution & Light pollution \\
\hline & & Water pollution & Water pollution \\
\hline & & Air pollution & Dust pollution, odor pollution \\
\hline & & Waste pollution & Waste emissions \\
\hline
\end{tabular}

for weight allocation. It was originally designed for marketing studies of consumption preference, and it was later introduced to house selection, city planning and policy making in the 1970 s (Nordh, Alalouch, \& Hartig, 2011; Knight and Menchik, 1974). Currently, the SP method is mostly applied in the field of transportation. For example, it is used to analyze and predict the selection of traveling modes and berths (Jiang and Li, 2009; Zhao et al., 2000). The use of this method to assess the urban environment has just begun, and the current focus is on urban residential area environmental assessment methodology (Wang \& Li, 2006; Zhang, 2007; Zhao, Wang, \& Zhu, 2013). This method infers weights from respondent preferences collected from surveys, therefore it is more consistent with people's process to judge and select and thus considered as more scientific. Hence it avoids arbitrariness that is characteristic of subjective methods and it also avoids being heavily dependent on data which can be a challenge in objective methods. With these reasons, the SP method was chosen for allocation of weights for urban commercial district environmental performance assessment.

The SP method satisfies the theoretical conditions for the discrete choice model, because it acquires the relative importance of influences from different environmental factors by asking customers to choose the environment where they would like to shop. So the discrete choice model was used here for data analysis. The discrete choice model, i.e. the choice-based conjoint analysis model, analyzes the data through the multinomial logit model.

The multinomial logit model assumes that each respondent chooses a scenario (commercial environment) from the option set $C$ of $\mathrm{m}$ available scenarios. Its choice probability is equal to:

$\mathrm{P}\left(\mathrm{c}_{\mathrm{i}} \mid \mathrm{C}\right)=\frac{\exp \left(\mathrm{U}\left(\mathrm{c}_{\mathrm{i}}\right)\right)}{\sum_{\mathrm{j}=1}^{\mathrm{m}} \exp \left(\mathrm{U}\left(\mathrm{c}_{\mathrm{j}}\right)\right)}=\frac{\exp \left(\mathrm{x}_{\mathrm{i}} \beta\right)}{\sum_{\mathrm{j}=1}^{\mathrm{m}} \exp \left(\mathrm{x}_{\mathrm{j}} \mathrm{p}\right)}$

where $x_{i}$ is the indicator set of the scenario, $\beta$ is the unknown parameter vector. $U\left(c_{i}\right)=x_{i} \beta$ is the utility associated with choosing the scenario $c_{i}$ and it is the linear function of the indicators in this scenario. Therefore, the probability that a scenario is chosen by the respondent is equal to the exponential function value of this scenario's utility divided by the sum of exponential function values of utilities from all scenarios.

In the multinomial logit model, the maximum likelihood function is used to estimate the unknown parameter, vector $\beta$ :

$\mathrm{L}_{\mathrm{C}}(\dot{\beta})=\frac{\exp \left(\left(\sum_{\mathrm{j}=1}^{\mathrm{m}} \mathrm{f}_{\mathrm{jk}} \mathrm{x}_{\mathrm{j}}\right) \beta\right)}{\left(\sum_{\mathrm{j}=1}^{\mathrm{m}} \exp \left(\mathrm{x}_{\mathrm{j}} \beta\right)\right)^{\mathrm{N}}}$

$\mathrm{f}_{\mathrm{jk}}=\left\{\begin{array}{l}1 \\ 0\end{array}\right.$

where $\mathrm{N}$ is the number of respondents; $\mathrm{m}$ is the number of scenarios in the option set. If the kth respondent chooses the jth scenario, then $\mathrm{f}_{\mathrm{jk}}=1$, otherwise $\mathrm{f}_{\mathrm{jk}}=0$. The computed model parameter, $\beta$ from the multi logit model provides the estimation of the unknown parameter vector and the utility of each property (Huang and Shen, 2002).

Trial on results from the multinomial logit model consists of three parts. The first part pertains to the data structure summary table to check whether the data structure of the option set is correct and that the iterative algorithm for maximum likelihood estimate converges. The second part pertains to the model's fitting degree, performing significance test at the significance level $\alpha<0.05$, using the chi-square of the $-2 \log \mathrm{L}$ and the likelihood ratio statistics. The third part involves checking the estimate of each unknown parameter to examine the significance level (P-Value).

The market module in SAS 9.1.3, coupled with the discrete choice method, was used in this paper to fit various types of questions and the comprehensive scenario, obtaining the respondent (customer) based set of urban commercial district environmental assessment weights that are more consistent with people's judgment and selection process.

\section{Study area and survey method}

\subsection{Study area}

Beijing was selected for our case study because it is one of the largest and fast growing megacities in the world, and it has 
diversified, multi-level modern commercial modes. Moreover Beijing, being the capital of China, retains a rich and celebrated cultural heritage and profound commercial economic background. According to the results of our previous research about the identification and classification of urban commercial districts, the commercial districts in Beijing can be classified into five types based on their major function (Wang, Gao, \& Xu, 2015):

Dietary and cultural commercial districts are the gathering areas of all kinds of restaurants. Convenience commercial districts are to provide the necessities of life and basic services, including supermarkets, convenience stores, grocery stores, fast food restaurants, etc. Their service level is relatively lower, and the service object is mainly the nearby inhabitants. Shopping commercial districts are the districts with large shopping malls or central commercial streets as the core, accompanying the restaurants, clothing, cosmetics and some other type of specialty stores. They integrate with the function of shopping, entertainment, dining, etc, and in general they have higher service levels, larger service radius. Franchise-type commercial districts focus on a certain type of specialty merchandise sales. So they are single function and highly professional, such as construction material commercial district or appliances and electronics market. Complex commercial districts have kinds of formats and integrated functions, including integrated markets, various specialty stores, restaurants, etc. We selected one or two sampling areas for each type of commercial district: dietary and cultural commercial district in Wei Gong Cun, construction material commercial district in Shi $\mathrm{Li} \mathrm{He}$, shopping commercial district in Xi Dan, and in Xin Ao, convenience commercial district in Kan Dan Lu, and the complex commercial district in Hui Long Guan. Field study and questionnaire surveys were conducted in these sampling areas.

\subsection{Survey methods}

The indicators can be classified into two types according to the way of data collecting. One is the indicators that can be obtained by remote sensing interpretation and GIS spatial analysis, such as green space ratio, water area ratio, bus and metro accessibility (number of stations and distance from residents). The other is qualitative evaluation indicators such as open space quality, applicability of convenience facilities, etc. and these indicators were determined via questionnaires or field study. Weights of all the indicators were obtained through the SP (stated preference) survey.

\subsubsection{Indicator survey}

In the questionnaires, customers rated their levels of satisfaction and comfort, as well as impressions of the state of pollution using a five-point scale, i.e. very satisfied, moderately satisfied, satisfied, dissatisfied and very dissatisfied. In the field study, in order to eliminate subjectivity, detailed field study manuals were devised which thoroughly illustrate each indicator and the scores. Take the green landscape quality of the commercial district as an example, the manual specifies the following grades.

- Very good implies: the green land is very clean; the crown form of trees is very clear; there are a huge number of interesting landscapes of very high quality and aesthetic appeal.

- Moderately good implies: the green land is moderately clean, the crown form is moderately clear, there are a large number of interesting landscapes of moderately high quality and aesthetic appeal.

- Good implies: the green land is clean, the crown form is clear, there are some interesting landscapes of high quality and aesthetic appeal.
- Bad implies: some litter is left in the green land, and no interesting landscapes are available. Very bad implies: there is no green land or the green land is very untidy, and no interesting landscapes are available at all.

This enables the survey conductors to judge quickly without generating too much of subjectivity.

\subsubsection{SP survey}

In the SP survey, multiple values are pre-defined for each indicator. Combining these values can create different scenarios, each of which constitutes an option. Then, the survey evaluates the overall preference with regard to each option among respondents by asking the respondents to score, sort or select the options. Generally, the more preference information we get from the respondents the better results we can obtain. However, if too many questions are asked, the respondents are very likely to refuse or give incorrect answers. Based on this, the SP survey scenarios can be designed with the mathematical theory to alleviate or eliminate interdependence between properties and evaluate the degree of influence from multiple factors (Kachi, Kato, \& Hayashi, 2008; Boxall et al., 1996; Asami, 2006).

Usually, an indicator has two grades and the indicator of great interests can have more. Due to the large number of indicators in our work, to alleviate fatigue and aversion that respondents may have while answering the questions, all indicators are set to have two grades. For example, the grade of the green space coverage indicator is either high or low; the grade of the bus accessibility indicator is either convenient or inconvenient; the grade of the pollution indicator is either serious or minor.

Scenario composition refers to the design of options, generating proper survey options via effective combination of different properties (indicators) and grades and then providing them for respondents to choose. More than three indicators are required to be contained in the SP survey. But if too many indicators are offered, it may be too informative for respondents to answer, thereby affecting data accuracy. Theoretically, a combination of 3-6 properties is best suited for people to choose and compare (Zhao, Wang, \& Zhu, 2013).

The survey questions were classified into 7 categories according to the type and number of indicators: (1) environmental quality of nature, (2) environmental quality of transportation, (3) environmental quality of security facility, (4) environmental quality of management, hygiene and aesthetics, (5) social service amount, (6) environmental load of land and traffic, and (7) environmental load of pollution. This classification helped to reduce the number of questions in the questionnaire.

Different types of survey questions and corresponding grades were combined via orthogonal design. For instance, the environmental quality of nature has five indicators, each of which has two grades and therefore theoretically there are L8 $\left(2^{7}\right)$ orthogonal scenarios. After eliminating the scenarios that are obviously similar to others, six effective scenarios (i.e. virtual commercial district) were obtained finally, as shown in Table 2. Furthermore, the six effective scenarios were cross-combined to generate option sets, and again we excluded those that are obviously preferred to others and finally six effective option sets were obtained. The respondents were asked to choose their preference from these option sets (Table 3).

The same method was applied to other categories to generate the corresponding scenarios and option sets: six scenarios and six option sets for the environmental quality of transportation; six scenarios and six option sets for the environmental quality of security facilities; five scenarios and five option sets for the environmental quality of management, hygiene and aesthetics; five 
Table 2

Scenarios of natural environmental quality.

\begin{tabular}{|c|c|c|c|c|c|}
\hline Scenarios & $\begin{array}{l}\text { Green land } \\
\text { coverage }\end{array}$ & $\begin{array}{l}\text { Green landscape quality } \\
\text { (whether beautiful) }\end{array}$ & $\begin{array}{l}\text { Water } \\
\text { surface } \\
\text { ratio }\end{array}$ & $\begin{array}{l}\text { Water body landscape quality (whether water } \\
\text { landscapes, such as fountain and stream, are beautiful) }\end{array}$ & $\begin{array}{l}\text { Human comfort (degree of comfort with regards to } \\
\text { temperature, humidity and wind speed) }\end{array}$ \\
\hline 1 & low & beautiful & low & Ugly & Uncomfortable \\
\hline 2 & low & ugly & high & Beautiful & Uncomfortable \\
\hline 3 & low & ugly & low & Beautiful & Comfortable \\
\hline 4 & high & beautiful & low & Beautiful & Uncomfortable \\
\hline 5 & high & ugly & low & Ugly & Uncomfortable \\
\hline 6 & high & beautiful & high & Ugly & Comfortable \\
\hline
\end{tabular}

scenarios and five option sets for the social service amount; five scenarios and five option sets for the environmental load of land and traffic; seven scenarios and seven option sets for the environmental load of pollution. Considering that it is easy for people to compare the preference of similar scenarios but difficult to compare different category of scenarios, we devised comprehensive scenarios that combines different categories and the corresponding option set, finally acquiring eight scenarios and eight option sets to adjust weights of indicators of different categories.

Lastly, all these option sets were randomly combined to generate different questionnaires. To reduce the number of questions in each questionnaire, we generated 15 types of questionnaires in total, each type with three or four options sets. Then, the SP survey was appended to the basic information of the respondent and the environmental performance questions. Respondents were asked to choose the best option from the three or four options sets.

\section{Assessment results and analysis}

\subsection{Data sampling and computation}

In July, 2014, field study, network and mobile communicationbased investigation were performed on the aforementioned six case study commercial districts, acquiring 442 answers from respondents, 313 of which were collected via the network and mobile communication with the remaining 129 via field survey. By checking the IP addresses, answering time and the answering logics, invalid answers were eliminated, and 417 (94.3\%) are valid answers for analysis. In addition, five investigators scored the indicators for green land, water landscape, cleanness of road, quality of open spaces and facilities of each commercial district, according to the investigation manual. The investigators also collected information on the situation of car parking, crowdedness and public security of the commercial districts by discussing with relevant managers and businessmen. The objective data such as green space ratio, water area ratio, bus and metro accessibility about the indicators were collected via GIS and remote sensing interpretation. Finally, the data obtained from questionnaires, field trips and objective data computation were summarized, and then fused by the average dimensionless method (Ye, 2003):

Table 3

Option set of environmental quality scenarios for natural environment.

\begin{tabular}{lll}
\hline Option set & Option 1 & Option 2 \\
\hline Option set 1 & Commercial district 3 & Commercial district 4 \\
Option set 2 & Commercial district 6 & Commercial district 2 \\
Option set 3 & Commercial district 3 & Commercial district 5 \\
Option set 4 & Commercial district 1 & Commercial district 2 \\
Option set 5 & Commercial district 2 & Commercial district 4 \\
Option set 6 & Commercial district 1 & Commercial district 3 \\
\hline
\end{tabular}

$\mathrm{y}_{\mathrm{i}}=\frac{\mathrm{x}_{\mathrm{i}}}{\text { mean } \mathrm{x}_{\mathrm{i}}}$

where $y_{i}$ is average dimensionless value of $i$ indicator, $x_{i}$ is the value of $\mathrm{i}$ indicator, and the mean $\mathrm{x}_{\mathrm{i}}$ is the mean value of the $\mathrm{i}$ indicator.

\subsection{SP-based set of weights}

Based on the 417 valid questionnaires, the market module in SAS 9.1.3 was used to fit various types of indicators and the comprehensive indicators, respectively. The model fitting results and relative importance of indicators are shown in Table 4. The fitting results of the comprehensive properties are given in Table 5.

From the fitting results, it can be observed that the likelihood ratio chi-square trials of the discrete choice analysis performed on various types of properties and the comprehensive scenarios were all less than 0.05 , meeting the general level of significance. That is, the null hypothesis got rejected, meaning that various types of properties as well as the comprehensive property had an influence on the customers' selection of commercial districts (environmental performance). As for the significance of each property, over half of the properties were significantly not equal to zero at a significance level of 0.05 . If the significance level was reduced to 0.1 , then most indicators passed the significance test and the signs of the model's coefficients were as expected. But light pollution, accessibility of facilities and coordination of the commercial districts with surroundings were tested to have no influence on customers' selection of environmental performance of commercial districts. Therefore, we followed the choice made by respondents and deleted these three indicators from our evaluation and analysis.

After obtaining the values and weights of indicators, the scores of environmental quality, social \& economic value and environmental load for each commercial district were further computed by using Equation (1), thereby acquiring the environmental performance score CEE of each commercial district.

\subsection{Assessment results}

Table 6 displays our assessment results. In order to present in an intuitive manner, we generated a 2-dimensional and a 3-dimensional environmental efficiency map by defining the environmental quality, social \& economic value and the environmental load as the three coordinate axes, as shown in Fig. 1.

From the 2D environmental assessment result map, it can be seen that when $\mathrm{CEE}=2$, i.e. the sum of environmental quality (Q) and social \& economic value $(S)$ was equal to twice the environmental load (L), the environmental performance was regarded acceptable. The area towards the upper left of CEE $=2$ means that the sum of $Q$ and $S$ was greater than twice the $L$, and in this case the environmental performance was regarded as good. The closer it was to the upper left, the better the environmental performance. On the contrary, the area at the bottom right of $\mathrm{CEE}=2$ means that 
Table 4

SP-based model fitting results and relative importance of properties.

\begin{tabular}{|c|c|c|c|c|c|}
\hline Level-2 indicators & $\begin{array}{l}\text { Commercial district environmental } \\
\text { performance indicators }\end{array}$ & $\begin{array}{l}\text { Model } \\
\text { coefficient }\end{array}$ & $\begin{array}{l}\text { Significance } \\
\text { level }\end{array}$ & $\begin{array}{l}\text { Relative importance of } \\
\text { properties }\end{array}$ & $\begin{array}{l}\text { Adjusted relative importance } \\
\text { of properties }\end{array}$ \\
\hline \multirow[t]{5}{*}{ Natural environment } & Green land coverage & 0.20594 & 0.0187 & 0.077 & 0.023 \\
\hline & Green landscape quality & 0.68893 & 0.0051 & 0.257 & 0.078 \\
\hline & Water area ratio & 0.48616 & 0.0783 & 0.181 & 0.055 \\
\hline & Water landscape quality & 0.40658 & 0.0208 & 0.151 & 0.046 \\
\hline & Human comfort & 0.89798 & 0.0013 & 0.334 & 0.102 \\
\hline \multicolumn{6}{|c|}{ Likelihood Ratio: $\operatorname{Pr}>$ Chi-Square $=0.0075$} \\
\hline \multirow[t]{5}{*}{ Human environment(traffic) } & Bus convenience & 0.12551 & 0.0688 & 0.076 & 0.049 \\
\hline & Metro convenience & 0.43436 & 0.0198 & 0.533 & 0.340 \\
\hline & Berths in parking lot & 0.28093 & 0.0418 & 0.281 & 0.179 \\
\hline & Road area ratio & 0.04872 & 0.0111 & 0.049 & 0.031 \\
\hline & Traffic control & 0.11045 & 0.0594 & 0.061 & 0.039 \\
\hline \multicolumn{6}{|c|}{ Likelihood Ratio: $\operatorname{Pr}>$ Chi-Square $=0.0263$} \\
\hline \multirow{5}{*}{ Human environment(security facilities) } & Public security & 1.31328 & 0.0348 & 0.588 & 0.025 \\
\hline & $\begin{array}{l}\text { Whether the security facilities are } \\
\text { complete }\end{array}$ & 0.18241 & 0.0494 & 0.082 & 0.003 \\
\hline & Applicability of convenience facilities & 0.57808 & 0.0593 & 0.259 & 0.011 \\
\hline & Open space ratio and quality & 0.16018 & 0.0509 & 0.072 & 0.003 \\
\hline & Convenience of accessibility facilities & & & 0.000 & 0.000 \\
\hline \multicolumn{6}{|c|}{ Likelihood Ratio: $\operatorname{Pr}>$ Chi-Square $<0.0001$} \\
\hline \multirow{4}{*}{$\begin{array}{l}\text { Human environment (management, } \\
\text { hygiene and aesthetics) }\end{array}$} & Transaction processing ability & 0.53502 & 0.0149 & 0.310 & 0.004 \\
\hline & Street cleanness and maintenance & 0.92138 & 0.004 & 0.534 & 0.008 \\
\hline & Aesthetics of combined landscapes & 0.17723 & 0.0355 & 0.103 & 0.002 \\
\hline & Match with surroundings & & & 0.000 & 0.000 \\
\hline \multicolumn{6}{|c|}{ Likelihood Ratio: $\operatorname{Pr}>$ Chi-Square $=0.0147$} \\
\hline \multirow[t]{4}{*}{ Social \& economic value } & Historical and cultural significance & 0.24256 & 0.0096 & 0.181 & 0.181 \\
\hline & Local fame & 0.01068 & 0.0981 & 0.008 & 0.008 \\
\hline & Size and number of shops & 0.44392 & 0.0778 & 0.331 & 0.331 \\
\hline & Types and grades of shops & 0.64595 & 0.0553 & 0.481 & 0.48 \\
\hline \multicolumn{6}{|c|}{ Likelihood Ratio: $\operatorname{Pr}>$ Chi-Square $=0.0397$} \\
\hline \multirow[t]{4}{*}{ Land traffic load } & Building coverage & -0.21556 & 0.0848 & 0.169 & 0.116 \\
\hline & Vehicular traffic & -0.61962 & 0.0446 & 0.485 & 0.333 \\
\hline & Local people traffic & -0.01212 & 0.0761 & 0.009 & 0.007 \\
\hline & Non-local people traffic & -0.42971 & 0.0028 & 0.336 & 0.231 \\
\hline \multicolumn{6}{|c|}{ Likelihood Ratio: $\operatorname{Pr}>$ Chi-Square $=0.0576$} \\
\hline \multirow[t]{6}{*}{ Pollution load } & Noise pollution & -1.28559 & 0.0012 & 0.319 & 0.099 \\
\hline & Light pollution & & & 0.000 & 0.000 \\
\hline & Sewage pollution & -1.00956 & 0.0022 & 0.251 & 0.078 \\
\hline & Dust pollution & -0.52801 & 0.0693 & 0.131 & 0.041 \\
\hline & Odor pollution & -0.13854 & 0.0092 & 0.034 & 0.011 \\
\hline & Waste pollution & -1.06767 & 0.0121 & 0.265 & 0.083 \\
\hline \multicolumn{6}{|c|}{ Likelihood Ratio: $\operatorname{Pr}>$ Chi-Square $<0.0001$} \\
\hline
\end{tabular}

Table 5

Model fitting result from the comprehensive scenario.

\begin{tabular}{|c|c|c|c|}
\hline Indicators & Model coefficient & Significance level & Relative importance \\
\hline Green land coverage & 0.38181 & 0.0527 & 0.14873 \\
\hline Bus convenience & 0.79583 & 0.0007 & 0.31000 \\
\hline Convenience facility applicability & 0.18147 & 0.0725 & 0.07069 \\
\hline Street cleaning and maintenance & 0.12501 & 0.0731 & 0.04870 \\
\hline Size and number of shops & 0.28937 & 0.0382 & 0.11272 \\
\hline Vehicular traffic & -0.61212 & $<0.0001$ & 0.23844 \\
\hline Noise pollution & -0.18155 & 0.0087 & 0.07072 \\
\hline Likelihood Ratio: $\operatorname{Pr}>$ Chi-Square & & & \\
\hline
\end{tabular}

Table 6

Environmental assessment of typical commercial districts.

\begin{tabular}{|c|c|c|c|c|c|c|}
\hline & Wei Gong Cun & Shi Li He & Xi Dan & Xin Ao & Kan Dan Lu & Hui Long Guan \\
\hline $\mathrm{Q}$ & 0.9963 & 0.9930 & 1.1419 & 1.4734 & 0.4050 & 0.9857 \\
\hline$S$ & 0.8184 & 1.2547 & 1.5162 & 0.9756 & 0.5528 & 0.8824 \\
\hline $\mathrm{L}$ & 1.0310 & 1.0186 & 1.1154 & 0.7987 & 1.0608 & 0.9755 \\
\hline CEE & 1.7601 & 2.2066 & 2.3830 & 3.0661 & 0.9029 & 1.9151 \\
\hline
\end{tabular}

$\mathrm{L}$ was greater than half of the $\mathrm{Q}+\mathrm{S}$, and in this case the environmental performance was regarded as unacceptable. The closer it is to the bottom right, the worse the environmental performance.
Therefore, the environmental performances of Xin Ao shopping commercial district, Xi Dan shopping commercial district and the Shi $\mathrm{Li} \mathrm{He}$ construction material commercial districts were 




(a)



(b)

Fig. 1. 2D and 3D pictorial display of environmental assessment of typical commercial districts.

acceptable, among which the environmental performance of Xin Ao shopping commercial district was over 3 and rated as good. The performances of Hui Long Guan and Wei Gong Cun were slightly below the acceptable limit, and Kan Dan Lu was far below the acceptable line, only receiving a score of 0.9 .

In the $3 \mathrm{D}$ environmental assessment result figure, $\mathrm{X}, \mathrm{Y}$ and $\mathrm{Z}$ axes represent $\mathrm{Q}, \mathrm{S}$ and $\mathrm{L}$, respectively. So the environmental performance in the AFEG cone was regarded unacceptable. The closer it is to point $\mathrm{E}$, the worse the environment; the closer it is to point $\mathrm{C}$, the better the environment. Thus, as in the 2D figure, the performances of Kan Dan Lu, Hui Long Guan and Wei Gong Cun were unacceptable. The ABFE plane in the 3D figure represents the relation between $\mathrm{Q}$ and $\mathrm{L}$, i.e. environmental quality efficiency of environmental load. The closer it was to point $\mathrm{E}$, the worse the environmental quality and the higher the environmental load; the closer it was to point $\mathrm{B}$, the better the environmental quality and the lower the environmental load. For the AFEG area, the environmental load was greater than the environmental quality, so the environment was considered unacceptable. It can be observed that the projection point of Xin Ao fell out of the AFEG cone, so it was acceptable. Xi Dan and Hui Long Guan were almost acceptable, whereas the others were unacceptable. Thus, some commercial districts had high environmental quality but their environmental loads were also very high, resulting in low environmental performances. An example is Xi Dan with its environmental quality of 1.14 and the environmental load of 1.12. The EADG plane represents the co-relation between $S \&$ L, i.e. socioeconomic efficiency of environmental load. The projection points of Xin Ao, Xi Dan and Shi Li He fell within the white area. This means that the social \& economic value of the commercial districts was greater than the environmental load, and that the environmental load of the social \& economic value was acceptable. The other three commercial districts were unacceptable, meaning that the commercial districts generated environmental loads but failed to bring about socioeconomic values in proportion. The $A B C D$ plane represents the co-relation between $\mathrm{Q}$ and $\mathrm{S}$. From this plane, it can be seen that the shopping commercial districts (Xi Dan and Xin Ao) were better than others with regards to these two aspects, and the Kan Dan Lu is not so good than the others.

From the evaluation results, we found that different types of commercial districts have different environmental performance due to their different functionality. So in the urban planning and management, we should take different measures for planning and administration accordingly. For instance, though the shopping commercial district has high environmental quality and social value, the environmental load is also very high, which leads to low environmental performance. So the planning and management of shopping commercial districts should pay more attention to reduce the environmental load, such as reasonable organization of customers and traffic; scientific site planning; decreasing environmental pollution, especially the noise pollution. The convenience commercial district is closely related place with the residents' daily life, but its environmental performance score is the lowest. Its environmental quality is the lowest and the environmental load is the highest. Therefore this kind of commercial district needs urgent unified planning and management for aspects such as layout of shops and infrastructure, the organization of traffic, and the management of sanitary and services, etc.

\section{Conclusions}

Drawing knowledge from existing environmental assessment of large scales and buildings, especially CASBEE and the environmental efficiency concept, this paper extends environmental assessment to urban commercial districts. Consideration is given to the environmental quality, social \& economic value, and environmental load. The SP survey method was incorporated to determine the weights of performance indicators.

The environmental assessment concept used in this paper is an extension of both the environmental performance assessment and the environmental efficiency assessment. It takes into account both the socioeconomic efficiency of the environment and the environmental efficiency. This fully illustrates its difference with the assessment on environmental quality or environmental load and it is capable of correcting people's proneness to consider only environmental quality or environmental load thereby broadening the understanding of environmental performance. In this context, areas of good environmentally quality may not have high environmental performance; areas with great environmental influence may generate high environmental quality and socioeconomic values.

Currently environment assessment is mostly conducted by the AHP or entropy methods. This paper introduced the SP survey 
method for assessment of commercial district environment. The weights of performance indicators were determined through the use of the SP survey questionnaires and the discrete choice model, and the model provides good fitting results. This method determined weights in a way more scientific and closer to respondents, effectively avoiding the dependence of AHP on subjective expert knowledge and also the dependence of the entropy method on data size and quality.

The assessment system proposed in this paper can assist for balancing several conflicting purposes of urban sustainability, like economic development, environmental quality and environmental constraint. The results of our research are helpful for understanding the environmental situation of urban commercial districts. Different kind of commercial districts have different performance, so they should take measures to improve environmental performance accordingly. For instance, shopping commercial districts should pay more attention to reduce the environmental load, through reasonable organization of customers and traffic; scientific site planning; decreasing environmental pollution, especially the noise pollution.

While in this paper we explored the environmental performance of urban commercial districts which are the one of the main meso-scale districts in a city, the idea of this assessment method can also be applied to other meso-scale districts, such as industrial districts and residential districts. By analyzing the general factors that influence the environmental performance of urban functional areas (meso-scale districts) and their spatial distribution in the city, one can generate the results that are instructive to city planning and management.

In this study we sampled only six commercial districts of Beijing. While the SP based weights for indicators can apply to all the other commercial districts in Beijing, difficulties in obtaining values for each indicator in each district prevented us from exploring more cases. In future research we plan to conduct city wide environmental assessments of commercial districts through more efficient data collection methods such as the internet data mining. In addition, uncertainty still exists in the conditionbased survey results. For example, the scenario description in the questionnaire may be potentially misleading. Further work needs to be done in this regard to make the SP method more reliable.

\section{Acknowledgment}

This work was partly supported by the grant from Japan Society for the Promotion of Science (KAKENHI No.26420634).

\section{References}

Asami Y. Translated by Gao Xiao-lu, Zhang Wen-zhong, et al, 2006, Living Environment: Assessment methodology and theories. (Tsinghua University Press, Beijing). (in Chinese).

Boxall, P., Adamowicz, W., Swait, J., Wllianms, M., \& Louviere, J. (1996). A comparison of stated preference methods for environmental valuation. Ecological Economics, 18(3), 243-253.

Charmondusit, K., \& Keartpakpraek, K. (2011). Eco-efficiency evaluation of the petroleum and petrochemical group in the map Ta Phut industrial estate, Thailand. Journal of Cleaner Production, 19(2), 241-252.

Dhakal, S. (2003). Assessment of local strategies for countering greenhouse gas Emissions: Case of Tokyo. http://www.doc88.com/p-813902704836.html.

Dizdaroglu, D. (2015). Developing micro-level urban ecosystem indicators forsustainability assessment. Environmental Impact Assessment Review, 2015(54) 119-124.

Du, D., Meng, X., \& Ma, F. (2012). Site selection assessment for river drinking source water of a city in northern. China Environmental Science, 32(2), 359-365 (in Chinese).
Esty, D. C., Levy, M. A., Kim, C. H., Sherbinin, A., Srebotnjak, T., \& Mara, V. (2008). Environmental performance index. New Haven: Yale Center for Environmental Law and Policy.

George, C., \& Kirkpatrick, C. (Eds.). (2007). Impact assessment and sustainable development: European practice and experience. Cheltenham: Edward Elgar.

Haapio, A. (2008). Environmental assessment of buildings. Doctoral Dissertation. Helsinki: Helsinki University of Technology.

Haapio, A. (2012). Towards sustainable urban communities. Environmental Impact Assessment Review, 32, 165-169.

Huang, G., \& Chen, Y. (1999). The application of the ecological method in urban planning take the planning of science city in Guangzhou as a case. Urban Planning, 23(6), 48-51 (in Chinese).

Huang, X., \& Shen, H. (2002). Application of discrete choice model in marketing research. Journal of Beijing broadcasting Institute. Science and Technology, 9(4), 34-42 (in Chinese).

ICF International. (2007). Greenhouse gases and air pollutants in the city of Toronto: Towards a harmonized strategy for reducing emissions. http://www.toronto.ca/ taf/pdf/ghginventory_jun07.

Ji, J., \& Gao, X. (2011). Method for evaluating environmental efficiency in urban residential areas. China Land Sciences, 25(10), 27-34 (in Chinese).

Jiang, Y., \& Li, T. (2009). Value of travel time: an SP survey in Tianjin. Urban Transportation, 7(2), 68-73 (in Chinese).

Kachi, N., Kato, H., \& Hayashi, Y. (2008). A system for evaluating spatial distribution of residential environment level by a QOL indicator based on generation spatial data. City planning review. Papers on City Planning, 43(3), 19-24 (in Japanese).

Knight, R. L., \& Menchik, M. D. (1974). Conjoint preference estimation for residential land use policy evaluation. Santa Monica, CA: RAND Corporation.

Lee, Y. J. (2007). Sustainability index for Taipei. Environmental Impact Assessment Review, 27, 505-521.

Lu, B., \& Cao, N. (2011). Environmental performance evaluation of Chinese urban form. Urban Planning, 18(7), 38-46 (in Chinese).

Marull, J., Pino, J., \& Mallarch, J. M. (2007). A land suitability index for strategic environmental assessment in metropolitan areas. Landscape and Urban Planning, 81, 200-212.

Mori, K., \& Christodoulou, A. (2012). Review of sustainability indices and indicators: towards a new city sustainability index. Environmental Impact Assessment Review, 32, 94-106.

Nordh, H., Alalouch, C., \& Hartig, T. (2011). Assessing restorative components of small urban parks using conjoint methodology. Urban Forestry and Urban Greening, 10(2), 95-103.

Putzhuber, F., \& Hasenauer, H. (2010). Deriving sustainability measures using statistical data: a case study from the Eisenwurzen. Austria. Ecol Indic, 10, 32-38.

Scipioni, A., Mazzi, A., Mason, M., \& Manzardo, A. (2009). The dashboard of sustainability to measure the local urban sustainable development: the case study of Padua municipality. Ecol Indic, 9, 364-380.

Seppalaa, J., Melanen, M., Maenpaa, I., Koskela, S., Tenhunen, J., \& Hiltunen, M. (2005). How can the eco-efficiency of a region be measured and monitored. Journal of Industrial Ecology, 9(4), 117-130.

Sev, A. (2011). A comparative analysis of building environmental assessment tools and suggestions for regional adaptations. Civil Engineering and Environmental Systems, 28(2), 231-245.

Sharifi, A. \& Murayama, A. (2013). A critical review of seven selected neighborhood sustainability assessment tools. Environmental Impact Assessment Review, 38, 73-87.

Wang, F., Gao, X., \& Xu, Z. (2015). An analytical tool for identifying and classifying the urban commercial district based on the urban block scale. Geography Research, 34(6), 1125-1134 (in Chinese).

Wang, D., \& Li, S. (2006). Socio-economic differentials and stated housing preferences in Guangzhou, China. Habitat International, 30, 305-326.

Wu, J., \& Wu, T. (2012). Sustainability indicators and indices. In Handbook of sustainable management. London: Imperial College Press.

Xu, L. (2006). Research on Green building assessment methodology and model. Tongji University (in Chinese).

Xu, X., Jin, F., \& Liu, H. (2010). Research progress on the resource and environment efficiency of industrial development. Progress in Geography, 29(12), 1509-1517( in Chinese).

Ye, Z. (2003). Selection of regularized and dimensionless methods for multiindicator comprehensive Assessmen. Zhejiang Statistics, 04, 25-26 (in Chinese).

Zaim, O. (2004). Measuring environmental performance of state manufacturing through changes in pollution intensities: a DEA framework. Ecological Economics, 48, 37-47.

Zhang, W. (2007). Index system and method of residential environment in inner cities. Scientia Geographica Sinica, 27(1), 17-23 (in Chinese).

Zhang, Y., Lu, W., Wang, W., Li, K., Xue, Y., \& Zhou, W. (2013). Research on optimum selection of rural domestic sewage treatment technology. China Environmental Science, 33(S1), 210-214 (in Chinese).

Zhao, P., Fujiwara, A., \& Sugie, Y. (2000). The application of stated preference survey method on traffic. Journal of Beijing Jiaotong University, 24(6), 29-32 (in Chinese).

Zhao, Q., Wang, De, \& Zhu, W. (2013). Quality of urban residential environment based on stated preference methods. Scientia Geographica Sinica, 3(1), 8-15 (in Chinese). 